\title{
Response to: Comment on "Failure of the Pipeline Embolization Device in Posterior Communicating Artery Aneurysms Associated with a Fetal Posterior Cerebral Artery"
}

\author{
Mario Zanaty, ${ }^{1}$ Nohra Chalouhi, ${ }^{2}$ Robert M. Starke, ${ }^{3}$ Pascal Jabbour, ${ }^{2}$ Katherine O. Ryken, \\ Ketan R. Bulsara, ${ }^{4}$ and David Hasan ${ }^{1}$ \\ ${ }^{1}$ Department of Neurosurgery, University of Iowa Hospital and Clinics, 200 Hawkins Drive, Iowa City, IA 52242, USA \\ ${ }^{2}$ Department of Neurological Surgery, Thomas Jefferson University and Jefferson Hospital for Neuroscience, 3rd Floor, \\ 901 Walnut Street, Philadelphia, PA 19107, USA \\ ${ }^{3}$ Department of Neurosurgery, University of Virginia, Charlottesville, VA 22908, USA \\ ${ }^{4}$ Department of Neurosurgery, Yale University, New Haven, CT 06519, USA
}

Correspondence should be addressed to David Hasan; david-hasan@uiowa.edu

Received 16 January 2017; Accepted 28 February 2017; Published 30 May 2017

Academic Editor: Boris Krischek

Copyright (C) 2017 Mario Zanaty et al. This is an open access article distributed under the Creative Commons Attribution License, which permits unrestricted use, distribution, and reproduction in any medium, provided the original work is properly cited.

We would like to thank Dr. Srinivasan and Dr. Kan for their remarks [1] on our paper [2]. We think that these publications were developed simultaneously. In addition, we think that more series would be reported in the future regarding the failure of the pipeline in the treatment of posterior communicating artery aneurysms associated with a fetal posterior cerebral artery. We also congratulate Srinivasan et al. [3] and Kan et al. [4] on their work on this topic and we agree that the most likely explanation of the pipeline failure is the high flow demand in this type of circulation. This can also explain why parent artery occlusion can lead to cerebellar infarction in this subset of patients [5]. We are also working on reporting other aneurysm geometrical factors that contribute to failure of flow-diversion; however this work is still in its early stages.

\section{Disclosure}

Robert M. Starke is currently affiliated to Department of Neurosurgery and Radiology, University of Miami, Coral Gables, FL, USA.

\section{Conflicts of Interest}

The authors declare that they have no conflicts of interest.

\section{References}

[1] V. M. Srinivasan and P. Kan, "Comment on 'failure of the pipeline embolization device in posterior communicating artery aneurysms associated with a fetal posterior cerebral artery", Case Reports in Vascular Medicine, vol. 2017, Article ID 1685358, 1 page, 2017.

[2] M. Zanaty, N. Chalouhi, R. M. Starke et al., "Failure of the pipeline embolization device in posterior communicating artery aneurysms associated with a fetal posterior cerebral artery," Case Reports in Vascular Medicine, vol. 2016, Article ID 4691275, 4 pages, 2016.

[3] V. Srinivasan, P. Kan, N. Mbabuike et al., "Oral Presentations 2016 AANS Annual Scientific Meeting Chicago, IL * April 30May 4, 2016," Journal of Neurosurgery, vol. 124, no. 4, pp. A1146A1209, 2016.

[4] P. Kan, E. Duckworth, A. Puri, G. Velat, and A. Wakhloo, “Treatment failure of fetal posterior communicating artery aneurysms with the pipeline embolization device," Journal of NeuroInterventional Surgery, vol. 8, no. 9, pp. 945-948, 2016.

[5] H. Matsumura, N. Kato, Y. Fujiwara et al., "Endovascular treatments for posterior cerebral artery aneurysms and vascular insufficiency of fetal-type circulation after parent artery occlusion," Journal of Clinical Neuroscience, vol. 32, pp. 41-46, 2016. 


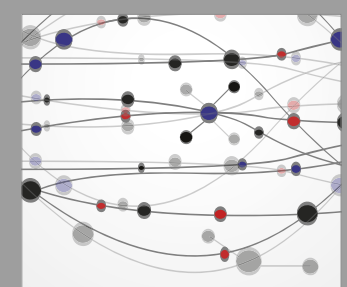

The Scientific World Journal
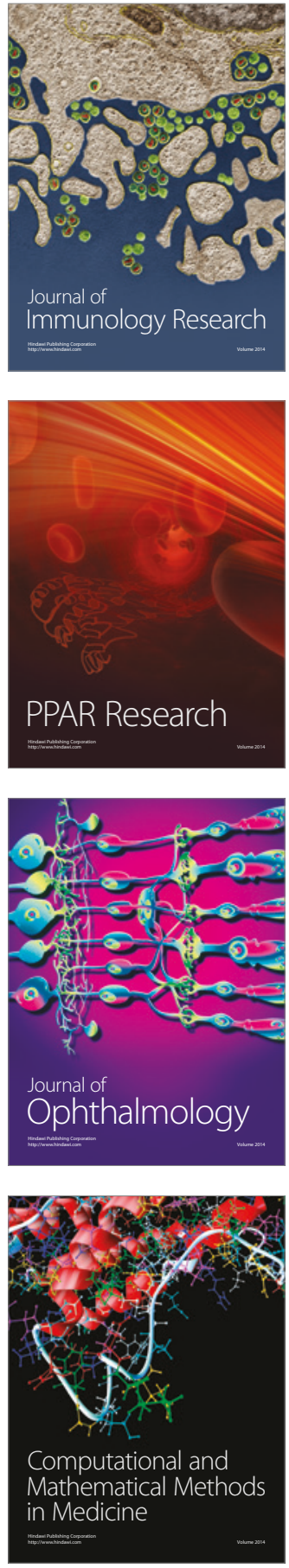

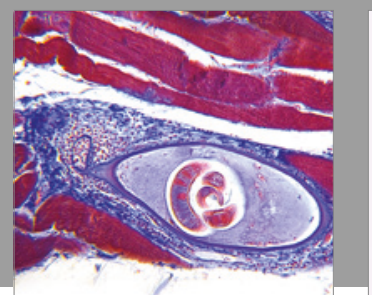

Gastroenterology Research and Practice
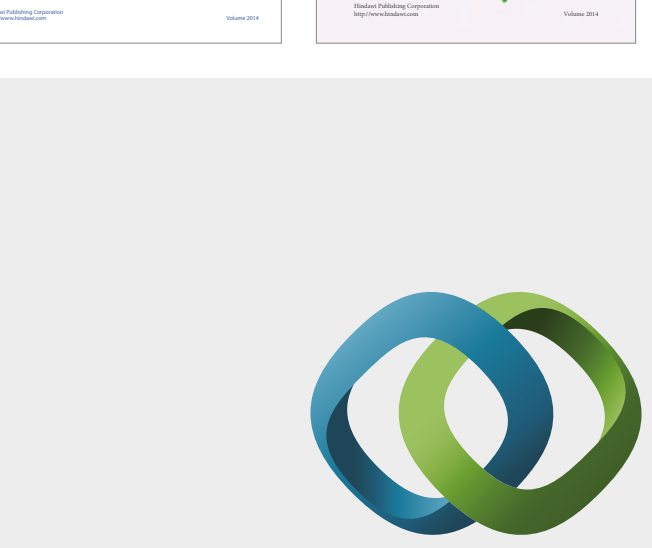

\section{Hindawi}

Submit your manuscripts at

https://www.hindawi.com
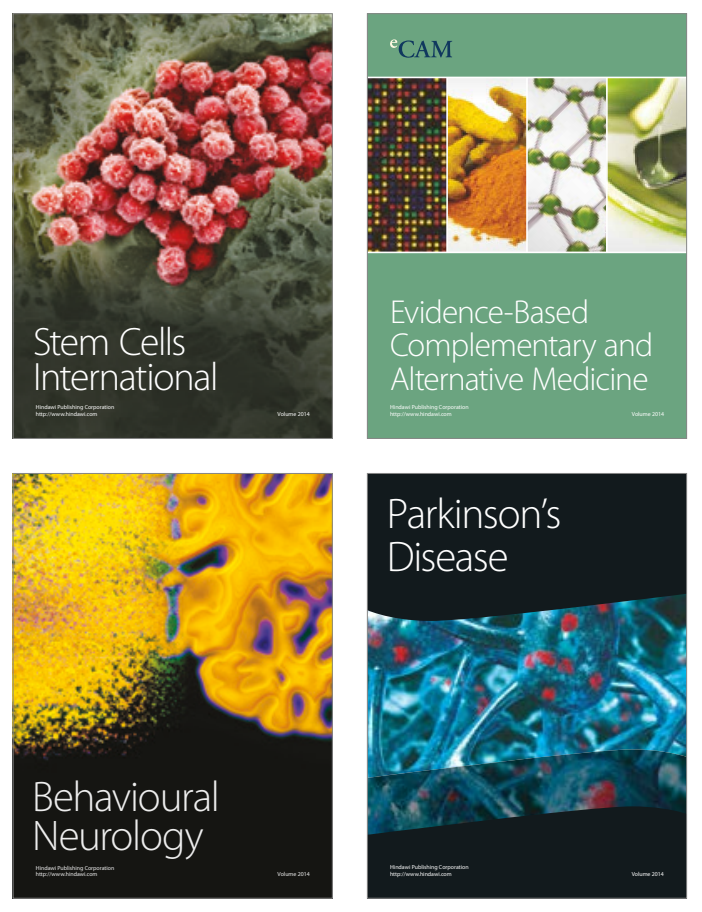
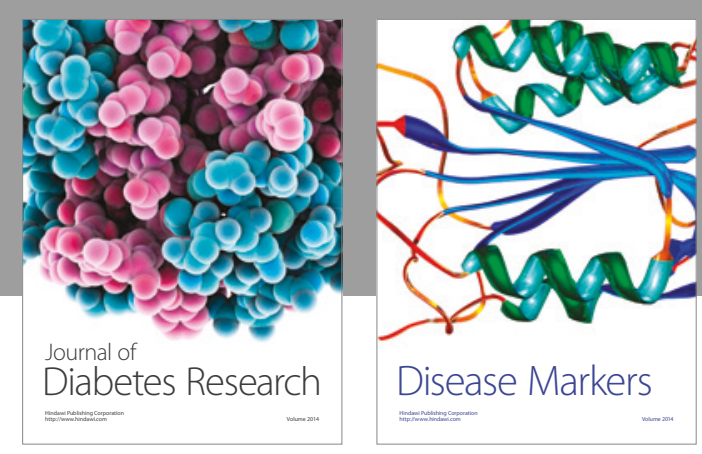

Disease Markers
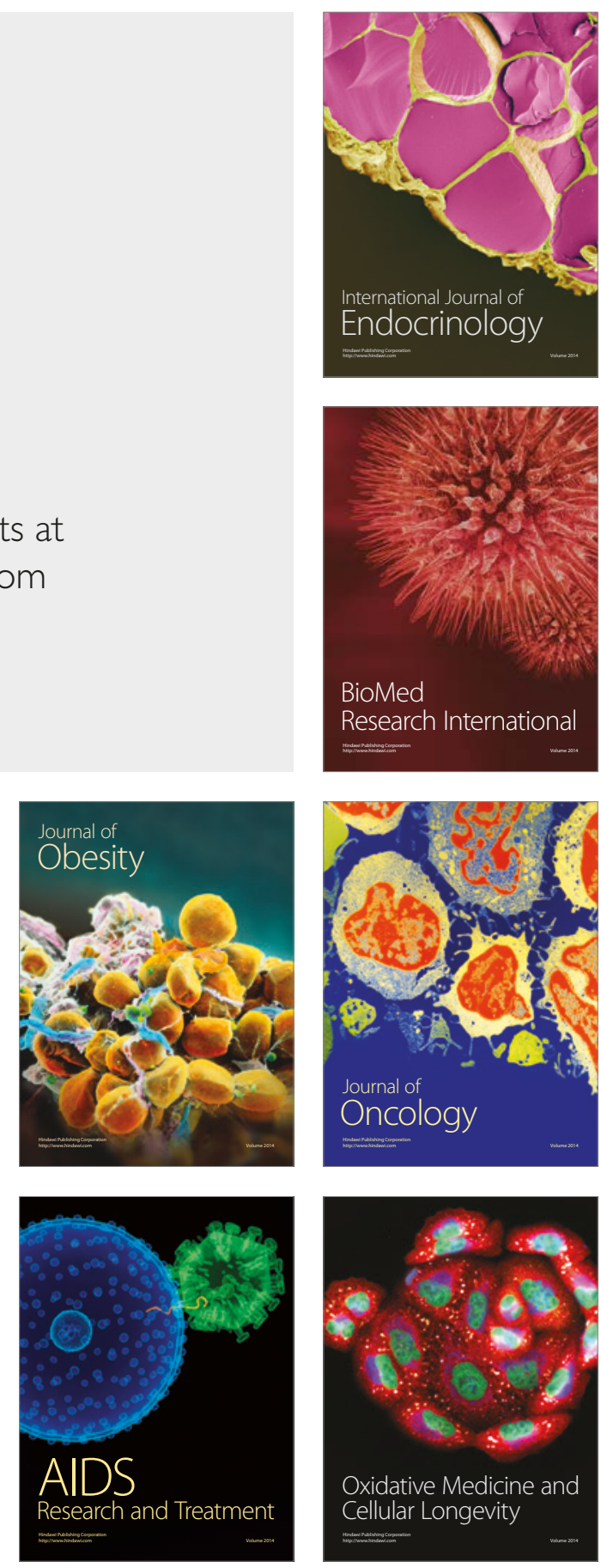